\title{
Cardiorenal Syndrome: Role of Arginine Vasopressin and Vaptans in Heart Failure
}

\author{
Poornima Vinod $^{\mathrm{a}}$, Vinod Krishnappa ${ }^{\mathrm{b}}$, Abigail M. Chauvin ${ }^{\mathrm{c}}$, Anshika Khare ${ }^{\mathrm{c}}$, \\ Rupesh Raina ${ }^{\mathrm{d}, \mathrm{e}}$
}

\begin{abstract}
Heart and kidney failure continued to be of increasing prevalence in today's society, and their comorbidity has synergistic effect on the morbidity and mortality of patients. Cardiorenal syndrome (CRS) is a complex disease with multifactorial pathophysiology. Better understanding of this pathophysiological network is crucial for the successful intervention to prevent advancement of the disease process. One of the major factors in this process is neurohormonal activation, predominantly involving renin-angiotensin-aldosterone system (RAAS) and arginine vasopressin (AVP). Heart failure causes reduced cardiac output/cardiac index $(\mathrm{CO} / \mathrm{CI})$ and fall in renal perfusion pressures resulting in activation of baroreceptors and RAAS, respectively. Activated baroreceptors and RAAS stimulate the release of AVP (non-osmotic pathway), which acts on $V_{2}$ receptors located in the renal collecting ducts, causing fluid retention and deterioration of heart failure. Effective blockade of AVP action on $\mathrm{V}_{2}$ receptors has emerged as a potential treatment option in volume overload conditions especially in the setting of hyponatremia. Vasopressin receptor antagonists (VRAs), such as vaptans, are potent aquaretics causing electrolyte-free water diuresis without significant electrolyte abnormalities. Vaptans are useful in hypervolemic hyponatremic conditions like heart failure and liver cirrhosis, and euvolemic hyponatremic conditions like syndrome of inappropriate anti-diuretic hormone secretion. Tolvaptan and conivaptan are pharmaceutical agents that are available for the treatment of these conditions.
\end{abstract}

Keywords: Cardiorenal syndrome; Heart failure; Arginine vasopressin; Vasopressin receptor antagonists; Vaptans; Tolvaptan; Conivap$\tan$

Manuscript submitted May 9, 2017, accepted May 18, 2017

aDepartment of Internal Medicine, Cleveland Clinic Akron General, Akron, $\mathrm{OH}$, USA

${ }^{b}$ Cleveland Clinic Akron General/Akron Nephrology Associates, Akron, OH, USA

'Northeast Ohio Medical University, Rootstown, OH, USA

dDepartment of Nephrology, Cleveland Clinic Akron General, Akron, OH, USA

${ }^{e}$ Corresponding Author: Rupesh Raina, Adult-Pediatric Kidney Disease/Hypertension, Department of Nephrology, Cleveland Clinic Akron General and Akron Children's Hospital, Akron, OH, USA. Email: rraina@chmca.org

doi: https://doi.org/10.14740/cr553w

\section{Introduction}

Heart failure is one of the leading global health problems despite decades of substantial clinical research and innovations in its treatment. Globally, heart failure continues to be a major economic burden accounting for estimated $\$ 108$ billion annually, with the United States alone spending $\$ 30.7$ billion as per 2012 estimates [1], necessitating more extensive research in this arena in order to lower global healthcare burden. Heart and kidney failure often coexist and they share a common etiology; and their comorbidity is a poor prognostic indicator, correlating with high all cause mortality [2-4]. There are many pathophysiological factors involved deterioration of failing heart and efforts to inhibit those factors have beneficial effects on the morbidity and mortality $[2,3]$.

The recently coined term "cardiorenal syndrome" (CRS) expresses the two-directional intricate pathophysiological network between heart and kidney. CRS is defined as "disorders of the heart and kidneys whereby acute or chronic dysfunction in one organ may induce acute or chronic dysfunction of the other" [5]. Both heart and kidney are vital for the maintenance of hemodynamic stability, which involves complex hemodynamic and neurohormonal mechanisms such as autonomic nervous system (ANS), renin-angiotensin-aldosterone system (RAAS), arginine vasopressin (AVP) and endothelin [2]. Activations of these neurohormonal factors in heart failure trigger vicious cycle characteristic of CRS. The contribution of AVP to this vicious cycle of CRS is manifold (Fig. 1). Increased AVP levels in heart failure due to mechanisms explained later in this article lead to fluid retention via its actions on vasopressin $(\mathrm{v})_{2}$ receptors [6]. Also, stimulation of $\mathrm{V}_{1 \mathrm{a}}$ receptors by AVP causes peripheral vasoconstriction $[6,7]$. On the other hand, renal ischemia secondary to low cardiac output (CO) in heart failure results in activation of RAAS, which in turn stimulates the release of AVP [8]. All these combined effects of AVP lead to increase in preload and afterload resulting in further deterioration of heart failure and renal ischemia, and then eventually renal failure ensues. Severe renal failure also retains fluid precipitating heart failure. Studies have shown that pre-existing renal failure or worsening renal parameters in heart failure bears high mortality and efforts at renal recovery have better mortality rates [3].

Over time, several classifications of CRS have been put forth, one such classification described five subtypes by Ronco et al in 2008 after a concensus conference of the Acute Dialy- 


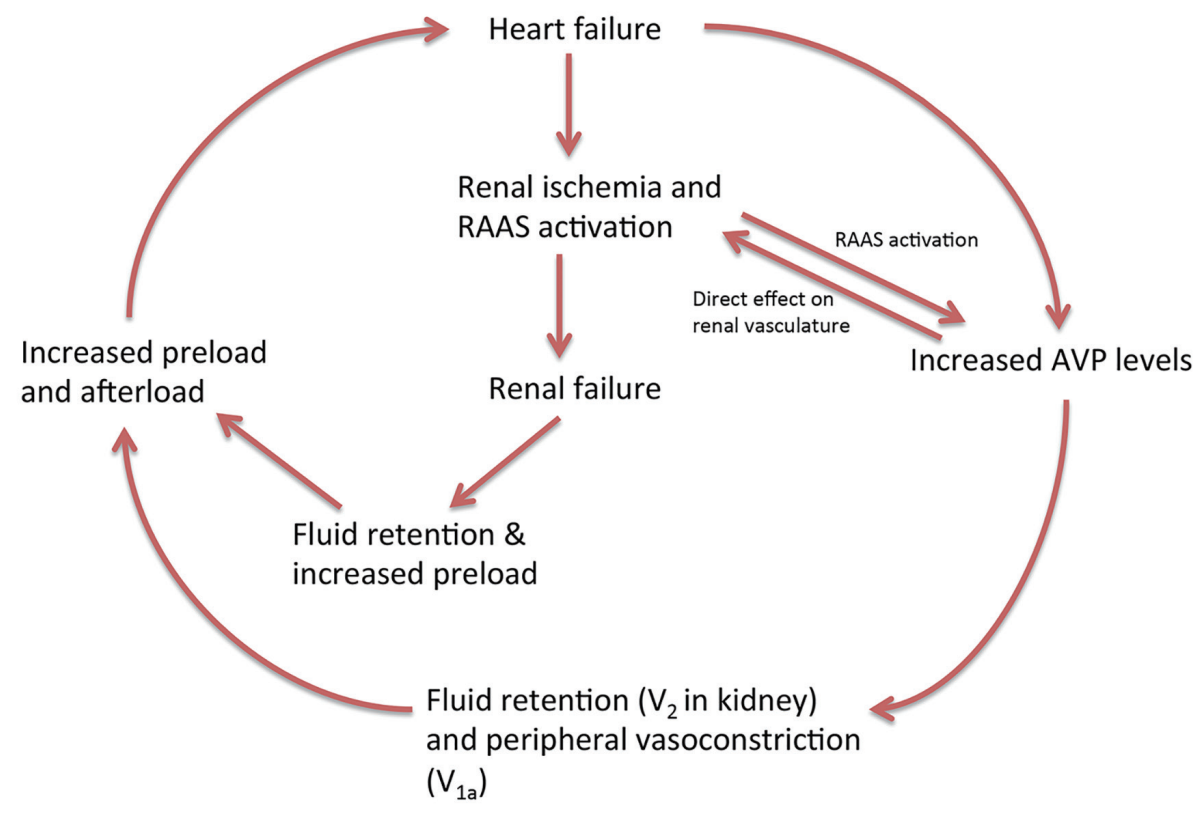

Figure 1. Vicious cycle involving heart, kidney and arginine vasopressin. RAAS: renin-angiotensin-aldosterone system; AVP: arginine vasopressin.

sis Quality Initiative (Fig. 2) [5]. This classification is based on the primary organ failure and whether the illness is acute or chronic, with a fifth subtype involving concomitant heart and kidney dysfunction secondary to systemic illness [5]. Recently, another classification system by Hatamizadeh et al recommended seven categories based on etiology (Fig. 3) that lends more insight into complex pathophysiology and multifactorial nature of CRS and indicates potential targets for future research $[2,9]$. This new etiological categorization accords a superior understanding of CRS and its management strategies [2,
9]. However, it is beyond the scope of this article to go further into details of CRS, and limit discussion to pathophysiology of AVP and role of vaptans in CRS.

\section{Pathophysiology of AVP in Heart Failure}

AVP is a peptide neuroendocrine hormone secreted from the hypothalamus and stored in posterior pituitary before its release in to circulation. Any AVP present in peripheral circula-

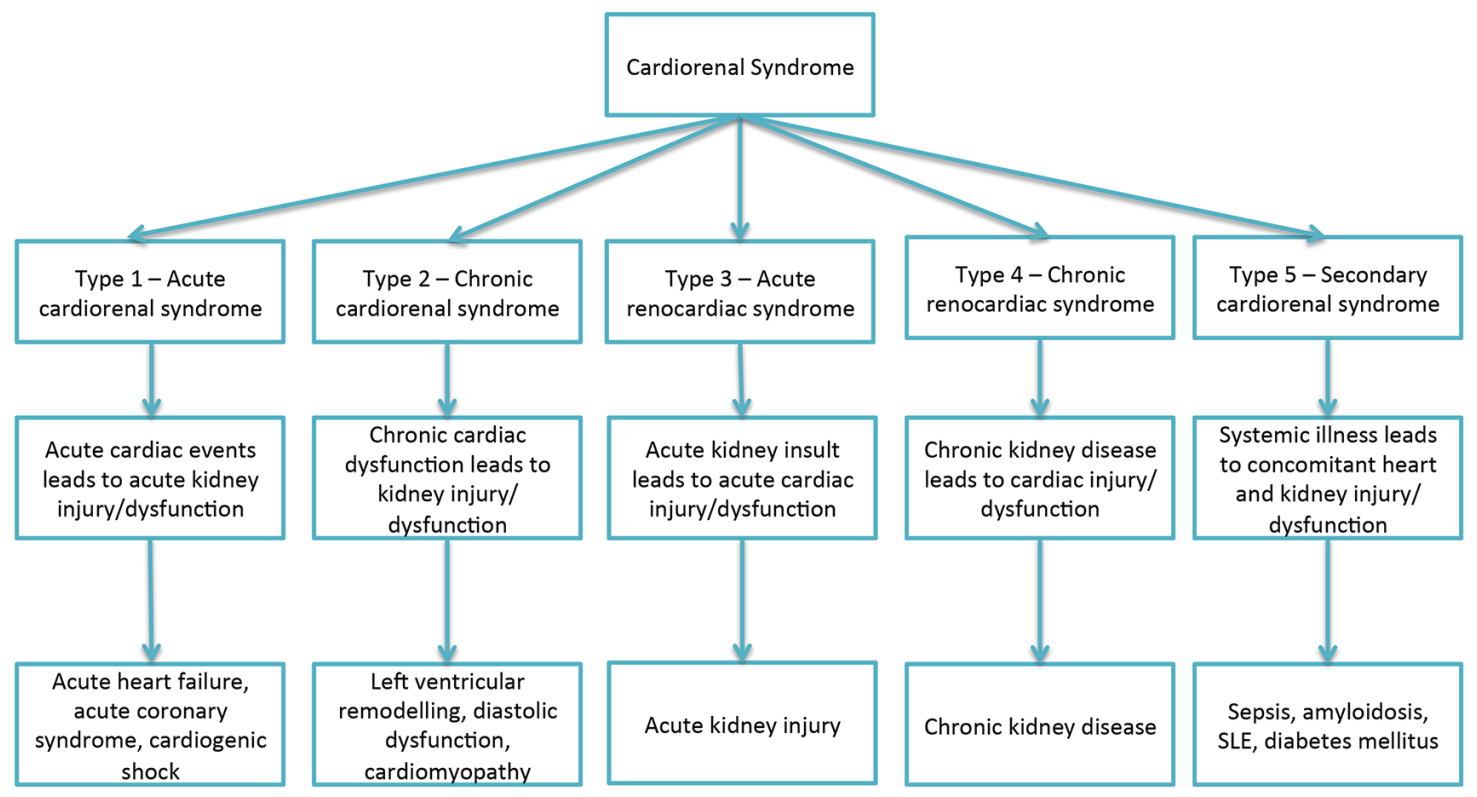

Figure 2. Classification of CRS based on primary organ failure by Ronco et al [5]. 


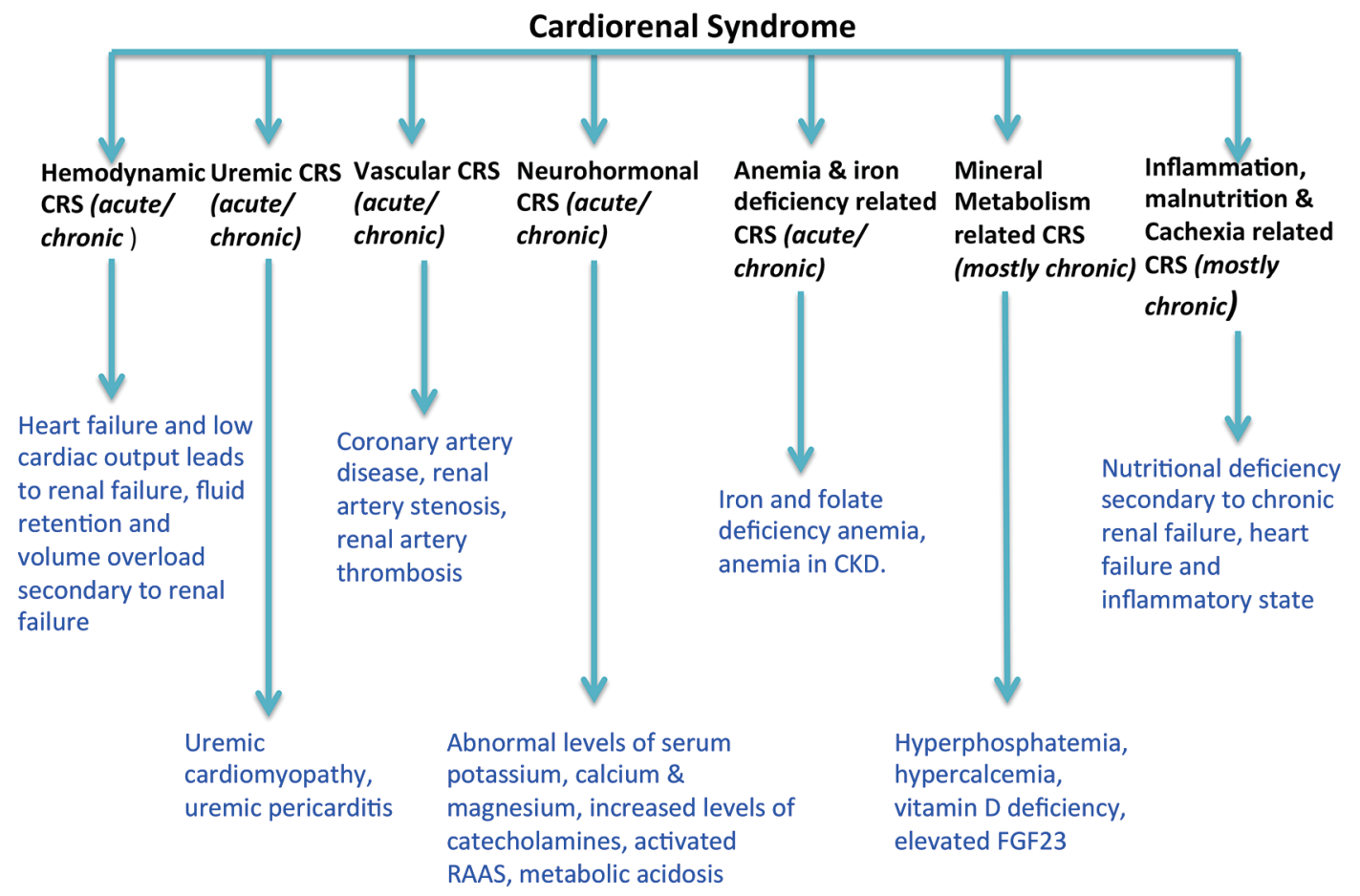

Figure 3. Pathophysiological classification of CRS by Hatamizadeh et al modified from references [2, 9]. RAAS: renin-angiotensin-aldosterone system; FGF23: fibroblast growth factor 23.

tion mainly originated from this source. AVP is also secreted from paraventricular nucleus of hypothalamus and travels down to anterior pituitary where, along with corticotropinreleasing hormone $(\mathrm{CRH})$, it stimulates production of adreno- corticotropic hormone (ACTH) [10]

Osmotic and non-osmotic pathways are the major regulators of AVP secretion (Fig. 4). Osmotic pathway involves changes in plasma osmolality sensed by hypothalamic osmore-

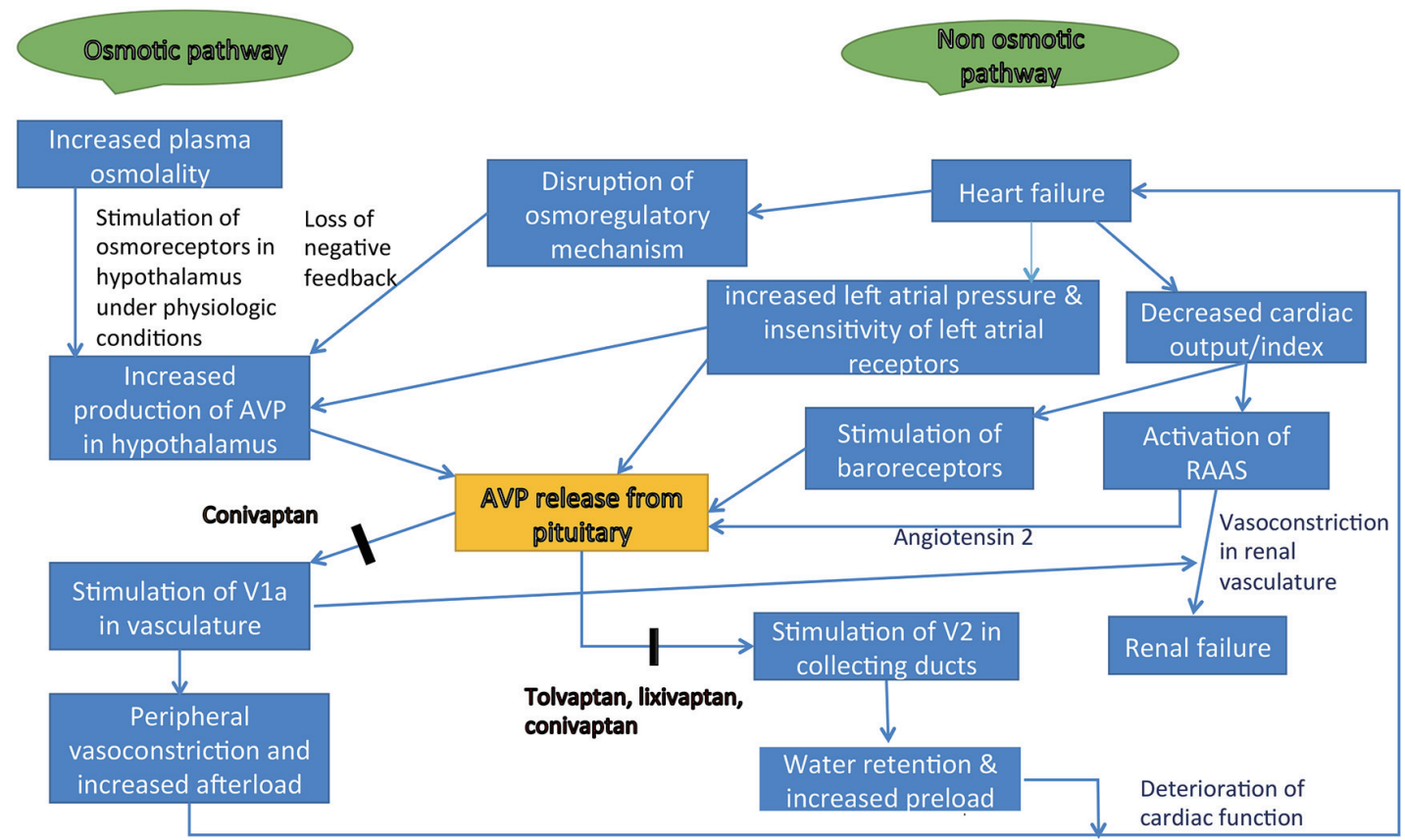

Figure 4. Schematic representation of mechanism of AVP regulation and actions. AVP: arginine vasopressin; RAAS: reninangiotensin-aldosterone system. 


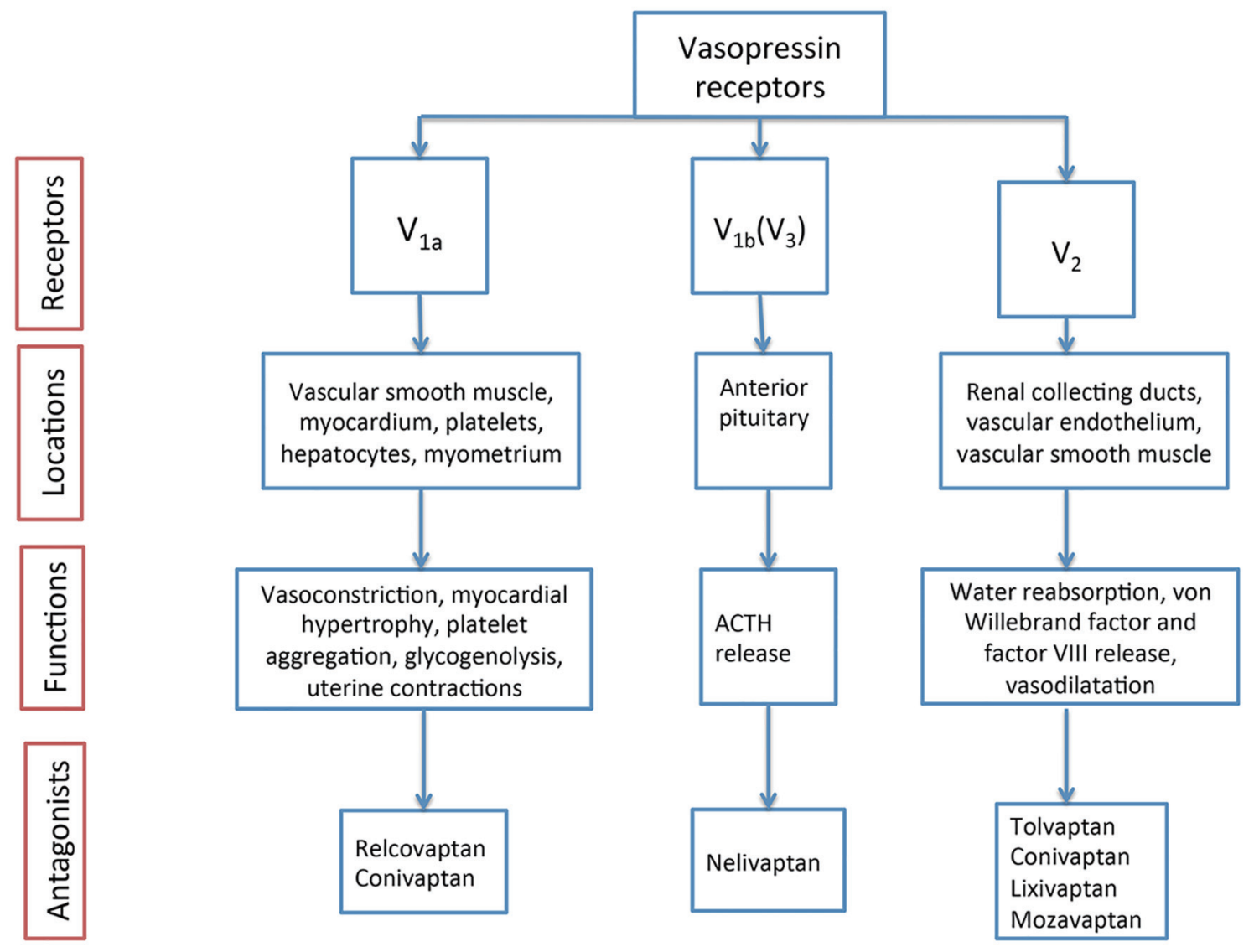

Figure 5. AVP receptors, their locations and antagonists [6, 7, 11, 12].

ceptors: a hyperosmolar state stimulates AVP release and hypoosmolar state inhibits AVP release [6]. Non-osmotic regulatory factors are baroreceptor stimulation, reduction in $\mathrm{CO} /$ cardiac index (CI) and activation of RAAS [6]. AVP exerts its actions via vasopressin receptors (Fig. 5), which are categorized into $\mathrm{V}_{1 \mathrm{a}}, \mathrm{V}_{1 \mathrm{~b}}\left(\mathrm{~V}_{3}\right)$ and $\mathrm{V}_{2} . \mathrm{V}_{1 \mathrm{a}}$ receptors are present in peripheral vasculature and myocardium, and are responsible for vasoconstriction and cardiac contractility. $\mathrm{V}_{1 \mathrm{~b}}$ receptors are present in the anterior pituitary and are responsible for ACTH secretion. $\mathrm{V}_{2}$ receptors reside in renal collecting ducts and are responsible for water retention $[6,7,11,12]$. Commonly used diuretics that act on the collecting ducts and terminal parts of the distal convoluted tubule are potassium-sparing agents, whereas the thiazide group act on the distal convoluted tubule and loop diuretics act on the thick ascending loop of Henle [13].

In the distal nephron, AVP activates epithelial sodium channels by post-translational mechanism through $\mathrm{V}_{2}$ receptors causing increased sodium reabsorption in experimental adrenalectomized mice [14]. AVP may also exert its fluid retention actions by interfering with hyaluronan turnover in renal medullary interstitium [15]. AVP regulates urea movement in the epithelium of terminal inner medullary collecting duct of the kidney and maintains osmotic equilibrium to prevent osmotic diuresis [16]. However, the role of renal medullary hyaluronan and urea transport mechanism in heart failure is not known [17]. It has also been speculated that AVP produces natriuretic effect by stimulation of oxytocin receptors in the renal medullary collecting ducts, possibly attributed to the structural similarities between neurohypophysial hormones [18]. This may be an effort to normalize plasma osmolality faster in situations of dehydration or hypernatremia [18].

\section{Non-osmotic pathway of AVP regulation}

In heart failure, sequential activation of the complex neurohormonal system results in gradual worsening of cardiac function, causing renal failure. This in turn leads to further deterioration of organ functions and induces a vicious cycle. One such mechanism is non-osmotic regulation of AVP, which plays a dominant role in heart failure $[6,8]$, especially in late stage and has been associated with poor prognosis [7]. Elevated levels of AVP in heart failure result from reduced $\mathrm{CO} / \mathrm{CI}$, and fall in both blood pressure and renal perfusion with subsequent activation of baroreceptors and RAAS, respectively [8]. Under normal condition AVP secretion is inhibited by elevated left atrial pressure but one study by Riegger et al speculated that insensitivity of left atrial receptors in severe heart failure and chronically elevated left atrial pressures result in higher AVP levels [8]. In another study, Goldsmith et al found that elevation in plasma AVP levels failed to relate to hypotension, low CO or RAAS activity. This study attributed increased levels 
of AVP to disruption of osmoregulatory mechanism in heart failure: there was coexistence of hyponatremia, which would inhibit AVP secretion by negative feedback mechanisms under normal physiological conditions [19]. A study by Emamura et al involving severe heart failure patients showed reversal of AVP regulation mechanism from a non-osmotic to osmotic pathway following hemodynamic improvement with ventricular assist device treatment and heart transplantation [6].

\section{Effects of raised AVP levels}

Elevated levels of AVP in heart failure have detrimental effects that result in progressive decline in cardiac function. AVP causes peripheral vasoconstriction and increases afterload via stimulation of $\mathrm{V}_{1 \mathrm{a}}$ receptors [7]. Also, stimulation of $\mathrm{V}_{2}$ receptors results in insertion of aquaporin-2 channels into renal collecting ducts, causing water retention and increased preload $[6,7]$. Both increase in preload and afterload causes progressive cardiac decompensation and drop in $\mathrm{CO}$ and perfusion pressures resulting in tissue hypoxia [6]. Direct effect of AVP on renal vasculature in conjunction with reduced $\mathrm{CO}$, hypotension and activated RAAS results in renal failure or further deterioration of renal function secondary to afferent renal arteriolar vasoconstriction and fall in renal perfusion pressures [8]. A significant percentage of heart failure patients have concomitant kidney injury and two separate meta-analyses by Damman et al and Smith et al showed that renal failure is an independent prognostic factor associated with high mortality rates in heart failure patients [3, 4].

\section{Hyponatremia in heart failure}

Hyponatremia is one of the commonly encountered clinical problems among heart failure patients with a prevalence of about 20\% upon hospitalization and has been associated with increased length of stay as well as in-hospital and post-discharge mortality rates [20]. Furthermore, hyponatremia is an independent predictor of mortality, and closely associated with increased risk of adverse events and higher re-hospitalization rates [21]. Activation of RAAS, disproportionately high levels of AVP and other neurohormonal mechanisms involved in complex heart failure syndrome may all contribute to the development or worsening of hyponatremia [20]. Hyponatremia in heart failure is mainly dilutional secondary to neurohormonal activation especially AVP resulting in free water retention and volume overload [21]. Another less common cause of hyponatremia in the setting of heart failure is the use of diuretics such as spironolactone and loop diuretics. This is supported by a study where persistently low serum sodium levels correlated with the excessive use of loop diuretics and spironolactone [21]. Severity of hyponatremia may indicate the degree of underlying neurohormonal activation [20]. Almost always development of hyponatremia in heart failure is gradual and clinical manifestations are subtle in contrast to profound symptoms seen in abrupt hyponatremia [22]. Serum sodium levels $<125 \mathrm{mEq} / \mathrm{L}$ may manifest headache, nausea, gait disturbance and cognitive impairment [22]. Severe hyponatremia results in confusion, seizures and coma [22].
Correction of hyponatremia in the setting of heart failure is never urgent as it is a chronic condition and vasopressin receptor antagonists (VRAs) are the drugs of choice in this setting [22]. Acute hyponatremia develops in $<24-48 \mathrm{~h}$ and chronic hyponatremia develops in $>48 \mathrm{~h}$ or duration is unknown. Rapid restoration of serum sodium levels can be done in acute hyponatremia as brain would not have had enough time for adaptation to hyponatremia. In case of seizures and

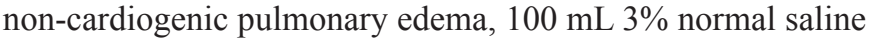
bolus is administered intravenously over $10 \mathrm{~min}$, which can be repeated if necessary for up to a maximum of three times [23$25]$. The goal is to correct $4-6 \mathrm{mEq} / \mathrm{L}$ quickly with remainder of correction over rest of the first $24 \mathrm{~h}$. In chronic hyponatremia, slow correction is recommended at a rate of $<12 \mathrm{mEq} / \mathrm{L}$ in the first $24 \mathrm{~h}$ and total of $<18 \mathrm{mEq} / \mathrm{L}$ in the first $48 \mathrm{~h}$ to prevent osmotic demyelination [23-25].

\section{Role of Vaptans in Heart Failure}

Vasopressin and endothelin play more active roles in the advancement of cardiorenal disease after neurohormonal blockade with existing therapies such as ARB/ACE inhibitors, betablockers and aldosterone antagonists [26]. To optimize heart failure treatment, there is a need to consider VRAs. Many therapeutic interventions including non-peptide VRA, vaptans (Fig. 5) have evolved over years in an effort to prevent adverse effects of neurohormonal activation and to improve outcomes in heart failure $[26,27]$. Apart from heart failure, vaptans are also useful in other hypotonic hyponatremic conditions such as syndrome of inappropriate antidiuretic hormone secretion (SIADH) and cirrhosis of liver [27]. Congestive heart failure (CHF) and liver cirrhosis manifest as hypervolemic hyponatremia whereas SIADH manifests as euvolemic hyponatremia. After over two decades of failed efforts in developing clinically effective peptide VRA [28], finally successful development of a non-peptide selective $V_{2}$ receptor antagonist with potent aquaretic properties was first reported in Japan in 1993 by Ohnishi et al [27]. This drug was tested on healthy men in comparison with a loop diuretic and shown to be equally effective with furosemide without any clinically significant electrolyte abnormalities. Vaptans play a vital role in the treatment of hypervolemic and euvolemic hyponatremia by promoting electrolyte-free diuresis through the kidneys via blockade of vasopressin receptors [27]. Vaptans are shown to restore serum sodium levels uneventfully [22]. However, vaptans are contraindicated in hypovolemic hyponatremia [22].

In patients with hyponatremic neurological symptoms where hypertonic saline is typically the first-line treatment, vaptans cannot be combined with hypertonic saline as there are reports of osmotic demyelination due to rapid restoration of serum sodium levels [22]. Furthermore, patients on vaptan therapy are at risk of hypernatremia due to rapid rise in serum sodium levels and close monitoring with an eye on sodium levels is warranted. In randomized placebo-controlled doubleblind SALT 1 and SALT 2 trials (Study of Ascending Levels of Tovaptan in Hyponatremia 1 and 2), overcorrection of serum sodium levels was observed in few patients but no serious 
adverse events like osmotic demyelination encountered [29]. However, caution should be exercised while using vaptans in situations where rapid restoration of serum sodium levels (> $8-12 \mathrm{mmol} / \mathrm{L} / 24 \mathrm{~h}$ ) is to be avoided. Hypernatremia secondary to vaptans can be managed by discontinuation of the drug since its half-life is $<12 \mathrm{~h}$ and hypotonic saline infusion could be an option if required until the drug effect weans off [28]. All the vaptans are cytochrome P450 3A4 inhibitors requiring caution and dosage adjustments when used with other drugs metabolized by this system such as benzodiazepines, atypical antipsychotics, warfarin, macrolides, other vaptans, amiodarone and cyclosporin [28]. Also, vaptans can cause severe hepatic injury necessitating close follow-up on liver functions and should be avoided in patients with liver disorders [22]. They are also contraindicated in anuric renal failure. Presently in the United States, tolvaptan and conivaptan are approved for use in heart failure with hyponatremia and a summary of the studies involving these two drugs are presented in Table 1 [26, 29-36].

\section{Conivaptan}

Conivaptan is a non-selective $\mathrm{V}_{1 \mathrm{a}}$ and $\mathrm{V}_{2}$ antagonist available as intravenous preparation for in-hospital use. By blocking $\mathrm{V}_{\text {1a }}$ and $\mathrm{V}_{2}$, peripheral vasodilatation and electrolyte-free diuresis are induced, reducing preload and afterload to result in improved $\mathrm{CO}$ in patients with heart failure [26,37]. It also has favorable effects on ventricular remodeling and myocardial hypertrophy due to $\mathrm{V}_{1 \mathrm{a}}$ antagonism [37]. A multicenter randomized controlled trial involving 142 symptomatic heart failure patients showed that conivaptan induces diuresis without any alteration in mean arterial pressure, heart rate or serum electrolytes [26]. However, reductions in pulmonary capillary wedge pressure and right atrial pressure were noticed. This study theorized these effects may be attributed to increased urine output by $\mathrm{V}_{2}$ receptor blockade and direct antagonism of $\mathrm{V}_{1 \mathrm{a}}$ receptors in the myocardium [26]. Recently, a study by Zeynalov et al showed intravenous conivaptan administration for $48 \mathrm{~h}$ improves blood brain barrier function, cerebral edema and neurological deficits following experimental stroke in mice. This finding could lead to future treatment options in ischemic stroke patients [38]. Another recent study by Palmer et al involving 251 subjects with hyponatremia showed that conivaptan administered in two different dose regimens (20 and $40 \mathrm{mg}$ /day for 4 days following a $20 \mathrm{mg}$ loading dose) has similar efficacy in euvolemic subjects compared to hypervolemic subjects [30]. However, hypervolemic subjects showed better results with higher $(40 \mathrm{mg} /$ day $)$ dose regimen with respect to rate of increase in serum sodium and duration of effect [30]. Both of these regimens were well tolerated and the most common adverse effect was infusion-site reaction. There was no significant increase in rate of adverse effects profile with 40 $\mathrm{mg}$ /day dose compared to $20 \mathrm{mg} /$ day dose group [30].

\section{Tolvaptan}

Tolvaptan is a selective $\mathrm{V}_{2}$ antagonist which has been extensively studied for its beneficial effects in heart failure and other conditions associated with hyponatremia. The biggest well-powered study, EVEREST outcome trial (The Efficacy of Vasopressin Antagonism in Heart Failure Outcome Study With Tolvaptan) involving 4133 patients, concluded that patients with heart failure who were started on tolvaptan in addition to standard therapy within $48 \mathrm{~h}$ of presentation to hospital, showed no change in long-term mortality or morbidity [32]. However, evidence was found of favorable short-term benefits such as increase in serum sodium levels, unaltered kidney function, weight loss, and symptomatic improvement [32]. On the contrary, a study involving 240 heart failure subjects showed that the long-term use of tolvaptan for a period of 1 year was safe and well tolerated, associated with no change in renal function or serum electrolytes, and has better mortality and morbidity rate compare with the control group [33]. Also, there was no effect on ventricular remodeling during selective $\mathrm{V}_{2}$ antagonism, which undermines the importance of unopposed $V_{1 \mathrm{a}}$ stimulation [33]. In SALT-1 and SALT-2 trials carried out in the outpatient setting, tolvaptan has been shown to be effective in dose-dependent correction of euvolemic or hypervolemic hyponatremia [29]. In two separate doubleblind, randomized, controlled trials, addition of tolvaptan to conventional diuretic therapy in patients with congestive heart failure led to raised urine output and restoration of serum sodium levels in hyponatremic subjects [36] without changes in renal functions or serum potassium [31]. However, a net increase in dose-dependent urinary sodium loss was noted and attributed to volume-driven loss [31]. In our view, this net sodium loss may also be due to proportional increase in the availability of AVP for speculated oxytocin receptor-mediated natriuresis [18]. Recently, a small study demonstrated echocardiographic features associated with initiation of tolvaptan therapy in patients with conventional diuretic resistant heart failure [34]. These characteristics were a dilated left atrium, dilated inferior vena cava and severe tricuspid incompetence [34]. Efficacy of tolvaptan in chronic kidney disease patients has been studied and shown to be beneficial in producing effective diuresis in volume overload conditions without deterioration in renal functions, which are associated with conventional diuretic therapy [35]. Recently, three separate systematic review and meta-analyses concluded that short- and long-term use of tolvaptan in heart failure was safe, has beneficial effects with respect to weight loss, high urine output, symptomatic improvement and restoration of serum sodium level without alteration in kidney function or serum electrolytes. Hyponatremic subgroup was shown to have improved mortality rates, although there were no mortality benefits associated with the use of tolvaptan [39-41].

\section{Conclusion}

CRS is a complex disorder involving various neurohormonal networks resulting in worsening of cardiac function. Effective interruption of the vicious cycle underlying this neurohormonal activation is challenging. Vasopressin antagonists (vaptans) are emerging as one of the most effective interventions in attenuating neurohormonal activation. Both conivap- 
Table 1. Clinical Trials of Vaptans

\begin{tabular}{lll}
\hline Study & Drug & No. of subjects \\
\hline Udelson et al (2001) [26] & Conivaptan & $\begin{array}{l}\text { Total } 142 \text { patients (38 received } \\
\text { placebo, } 37 \text { received } 10 \mathrm{mg}, 32\end{array}$ \\
Randomized double- & & $\begin{array}{l}\text { received } 20 \mathrm{mg}, \text { and } 35 \text { received } 40 \\
\text { blind trial }\end{array}$ \\
& & $\mathrm{mg})$
\end{tabular}
Clinical characteristics
Outcome
Symptomatic heart failure, Dose dependent diuresis
NYHA class III and IV.
Baseline serum creatinine
$1.1-1.3 \mathrm{mg} / \mathrm{dL}$. Patients
with serum creatinine $>$
$2.5 \mathrm{mg} / \mathrm{dL}$ or creatinine clearance $<30 \mathrm{~mL} / \mathrm{min} \mathrm{w}$
excluded from the study.
with no change in BP, HR
or serum electrolytes.
Reduction in PCWP and right atrial pressure due to direct myocardial $\mathrm{V}_{1 \mathrm{a}}$ receptor blockade and diuresis secondary to $V_{2}$ receptor.

$\begin{array}{lll}\text { Palmer et al (2016) [30] } & \text { Conivaptan } & \begin{array}{l}\text { Total } 251 \text { patients }(37 \text { received } 20 \\ \text { Open label }\end{array} \\ \text { multicenter study } & & \end{array}$

Gheorghiade et al

Tolvaptan

Total 254 patients $(63$ received placebo, 64 received $30 \mathrm{mg} / \mathrm{day}, 64$ received $45 \mathrm{mg}$ /day and 63 received $60 \mathrm{mg} /$ day)

Double-blind placebo controlled trial

Schrier et al (2006) [29] Multicenter, randomized, double-blind, placebocontrolled trials (SALT 1 and SALT 2)

Konstam et al (2007) [32] Tolvaptan The EVEREST outcome trial. Randomized, doubleblind, placebo-controlled trial

Tolvaptan

Total 448 patients (225 received 15 $\mathrm{mg} /$ day and later increased to $30 \mathrm{mg} /$ day and then to $60 \mathrm{mg}$ /day depending on serum $\mathrm{Na}^{+}$levels)

Euvolemic or hypervolemic

Total 4,133 patients $(2,072$ received $30 \mathrm{mg} /$ day and 2,061 received placebo)

Udelson et al (2007) [33] Multicenter, randomized, double-blind, placebocontrolled trial

Nakada et al (2015) [34]

Tolvaptan

Total 206 patients (26 conventional diuretic resistant patients received tolvaptan and 180 received conventional diuretic therapy) Total 240 patients (120 received 30
$\mathrm{mg} /$ day and 120 received placebo)

Retrospective study
Tolvaptan
Euvolemic or hypervolemic hyponatremia patients (majority are heart failure and SIADH, some are unknown cause). Patients with eGFR $<20 \mathrm{~mL} / \mathrm{min}$ were excluded from the study.

\section{Congestive heart failure} patients, NYHA class I-IV. Patients with serum creatinine $>3 \mathrm{mg} / \mathrm{dL}$ and BUN $>60 \mathrm{mg} / \mathrm{dL}$ were excluded from the study. hyponatremia patients (heart failure, cirrhosis, SIADH). Patients with serum creatinine $>3.5 \mathrm{mg} / \mathrm{dL}$ were excluded from the study.

Congestive heart failure patients, NYHA class III and IV. Patients with serum creatinine $>3.5 \mathrm{mg} / \mathrm{dL}$ were excluded from the study.

Heart failure patients, NYHA II and III with EF < $30 \%$. Patients with serum creatinine $>3 \mathrm{mg} / \mathrm{dL}$ and BUN $>60 \mathrm{mg} / \mathrm{dL}$ were excluded from the study.

Acute heart failure patients

Both the dose regimens are equally efficacious and well tolerated with infusion site reaction as the common side effect. of serum $\mathrm{Na}^{+}$levels without any change in $\mathrm{BP}, \mathrm{HR}$, serum $\mathrm{K}^{+}$or renal function when added to standard therapy

Effective dose-dependent correction of hyponatremia when added to standard therapy

No mortality or morbidity benefits when added to standard therapy.

Short-term benefits observed were weight loss, improvement in symptoms, and restoration of serum functions.

Long-term use for a period of one year is safe and well tolerated with better mortality and morbidity rate. No change in renal function or serum electrolytes observed. No effect on ventricular remodeling

Dilated left atrium and inferior vena cava, and severe tricuspid incompetence are frequently associated findings in acute heart failure patients who need tolvaptan therapy.

Volume overload due to CKD. In addition, few patients with heart and liver failure.

Acute decompensated heart failure with hyponatremia. Patients with serum creatinine $>3 \mathrm{mg} / \mathrm{dL}$ were excluded from the study.

\section{Effective diuresis without} deterioration in renal functions

Increased urine output and restoration of serum $\mathrm{Na}^{+}$levels when added to standard therapy
Increased urine output, restoration $\mathrm{Na}^{+}$levels with no change in renal

\begin{abstract}
Tanaka et al (2015) [35] Prospective study

(2016) [36

placebo-controlled trial
\end{abstract}

\section{Tolvaptan Total 20 patients}

Tolvaptan for 5 days
Total 51 patients $(26$ received placebo and 25 received $15 \mathrm{mg}$ /day) 
tan and tolvaptan are effective in the treatment of euvolemic and hypervolemic hyponatremia. Tolvaptan can be used safely in heart failure in short and long term, and has beneficial effects in weight reduction, increasing urine output, improving symptomatology and normalizing serum sodium level without alteration in kidney function and serum electrolytes. There are no mortality benefits related to the use of tolvaptan, although there is some evidence that a hyponatremic subgroup may have improved mortality rates.

\section{Author Contributions}

All authors have participated in all the stages of preparation of this manuscript. All the authors have reviewed the final version of the manuscript and approved for publication.

\section{Conflicts of Interest}

Authors have no conflicts of interest to declare.

\section{Funding}

This research received no specific grant from any funding agency in the public, commercial, or not-for-profit sectors.

\section{References}

1. Cook C, Cole G, Asaria P, Jabbour R, Francis DP. The annual global economic burden of heart failure. Int J Cardiol. 2014;171(3):368-376.

2. Obi Y, Kim T, Kovesdy CP, Amin AN, Kalantar-Zadeh K. Current and Potential Therapeutic Strategies for Hemodynamic Cardiorenal Syndrome. Cardiorenal Med. 2016;6(2):83-98.

3. Damman K, Navis G, Voors AA, Asselbergs FW, Smilde TD, Cleland JG, van Veldhuisen DJ, et al. Worsening renal function and prognosis in heart failure: systematic review and meta-analysis. J Card Fail. 2007;13(8):599-608.

4. Smith GL, Lichtman JH, Bracken MB, Shlipak MG, Phillips CO, DiCapua P, Krumholz HM. Renal impairment and outcomes in heart failure: systematic review and meta-analysis. J Am Coll Cardiol. 2006;47(10):1987-1996.

5. Ronco C, McCullough P, Anker SD, Anand I, Aspromonte N, Bagshaw SM, Bellomo R, et al. Cardio-renal syndromes: report from the consensus conference of the acute dialysis quality initiative. Eur Heart J. 2010;31(6):703711.

6. Imamura $\mathrm{T}$, Kinugawa $\mathrm{K}$, Hatano M, Fujino $\mathrm{T}$, Inaba $\mathrm{T}$, Maki H, Kinoshita O, et al. Low cardiac output stimulates vasopressin release in patients with stage $d$ heart failure. Circ J. 2014;78(9):2259-2267.

7. Niizuma S, Iwanaga Y. Revisiting vasopressin and heart failure. Expert Rev Cardiovasc Ther. 2013;11(11):14511454.
8. Riegger AJ, Liebau G. The renin-angiotensin-aldosterone system, antidiuretic hormone and sympathetic nerve activity in an experimental model of congestive heart failure in the dog. Clin Sci (Lond). 1982;62(5):465-469.

9. Hatamizadeh P, Fonarow GC, Budoff MJ, Darabian S, Kovesdy CP, Kalantar-Zadeh K. Cardiorenal syndrome: pathophysiology and potential targets for clinical management. Nat Rev Nephrol. 2013;9(2):99-111.

10. Salata RA, Jarrett DB, Verbalis JG, Robinson AG. Vasopressin stimulation of adrenocorticotropin hormone $(\mathrm{ACTH})$ in humans. In vivo bioassay of corticotropinreleasing factor (CRF) which provides evidence for CRF mediation of the diurnal rhythm of ACTH. J Clin Invest. 1988;81(3):766-774.

11. Decaux G, Soupart A, Vassart G. Non-peptide arginine-vasopressin antagonists: the vaptans. Lancet. 2008;371(9624):1624-1632.

12. Aditya S, Rattan A. Vaptans: A new option in the management of hyponatremia. Int J Appl Basic Med Res. 2012;2(2):77-83.

13. Odlind B. Site and mechanism of the action of diuretics. Acta Pharmacol Toxicol (Copenh). 1984;54(Suppl 1):515.

14. Mironova E, Bugaj V, Roos KP, Kohan DE, Stockand JD. Aldosterone-independent regulation of the epithelial $\mathrm{Na}+$ channel $(\mathrm{ENaC})$ by vasopressin in adrenalectomized mice. Proc Natl Acad Sci U S A. 2012;109(25):1009510100

15. Stridh S, Palm F, Hansell P. Renal interstitial hyaluronan: functional aspects during normal and pathological conditions. Am J Physiol Regul Integr Comp Physiol. 2012;302(11):R1235-1249.

16. Fenton RA. Essential role of vasopressin-regulated urea transport processes in the mammalian kidney. Pflugers Arch. 2009;458(1):169-177.

17. Jonsson S, Agic MB, Narfstrom F, Melville JM, Hultstrom M. Renal neurohormonal regulation in heart failure decompensation. Am J Physiol Regul Integr Comp Physiol. 2014;307(5):R493-497.

18. Shirley DG, Walter MF, Keeler BD, Waters NJ, Walter SJ. Selective blockade of oxytocin and vasopressin V(1a) receptors in anaesthetised rats: evidence that activation of oxytocin receptors rather than $\mathrm{V}(1 \mathrm{a})$ receptors increases sodium excretion. Nephron Physiol. 2011;117(3):p21-26.

19. Goldsmith SR, Francis GS, Cowley AW, Jr., Levine TB, Cohn JN. Increased plasma arginine vasopressin levels in patients with congestive heart failure. J Am Coll Cardiol. 1983;1(6):1385-1390.

20. Gheorghiade M, Abraham WT, Albert NM, Gattis Stough W, Greenberg BH, O'Connor CM, She L, et al. Relationship between admission serum sodium concentration and clinical outcomes in patients hospitalized for heart failure: an analysis from the OPTIMIZE-HF registry. Eur Heart J. 2007;28(8):980-988.

21. Gheorghiade M, Rossi JS, Cotts W, Shin DD, Hellkamp AS, Pina IL, Fonarow GC, et al. Characterization and prognostic value of persistent hyponatremia in patients with severe heart failure in the ESCAPE Trial. Arch Intern Med. 2007;167(18):1998-2005. 
22. Lehrich RW, Ortiz-Melo DI, Patel MB, Greenberg A. Role of vaptans in the management of hyponatremia. Am J Kidney Dis. 2013;62(2):364-376.

23. Verbalis JG, Goldsmith SR, Greenberg A, Schrier RW, Sterns RH. Hyponatremia treatment guidelines 2007: expert panel recommendations. Am J Med. 2007;120(11 Suppl 1):S1-21.

24. Sterns RH, Cappuccio JD, Silver SM, Cohen EP. Neurologic sequelae after treatment of severe hyponatremia: a multicenter perspective. J Am Soc Nephrol. 1994;4(8):1522-1530.

25. Verbalis JG, Goldsmith SR, Greenberg A, Korzelius C, Schrier RW, Sterns RH, Thompson CJ. Diagnosis, evaluation, and treatment of hyponatremia: expert panel recommendations. Am J Med. 2013;126(10 Suppl 1):S1-42.

26. Udelson JE, Smith WB, Hendrix GH, Painchaud CA, Ghazzi M, Thomas I, Ghali JK, et al. Acute hemodynamic effects of conivaptan, a dual V(1A) and V(2) vasopressin receptor antagonist, in patients with advanced heart failure. Circulation. 2001;104(20):2417-2423.

27. Ohnishi A, Orita Y, Okahara R, Fujihara H, Inoue T, Yamamura Y, Yabuuchi Y, et al. Potent aquaretic agent. A novel nonpeptide selective vasopressin 2 antagonist (OPC-31260) in men. J Clin Invest. 1993;92(6):26532659.

28. Greenberg A, Verbalis JG. Vasopressin receptor antagonists. Kidney Int. 2006;69(12):2124-2130.

29. Schrier RW, Gross P, Gheorghiade M, Berl T, Verbalis JG, Czerwiec FS, Orlandi C. Tolvaptan, a selective oral vasopressin V2-receptor antagonist, for hyponatremia. N Engl J Med. 2006;355(20):2099-2112.

30. Palmer BF, Rock AD, Woodward EJ. Dose comparison of conivaptan (Vaprisol(R)) in patients with euvolemic or hypervolemic hyponatremia - efficacy, safety, and pharmacokinetics. Drug Des Devel Ther. 2016;10:339-351.

31. Gheorghiade M, Niazi I, Ouyang J, Czerwiec F, Kambayashi J, Zampino M, Orlandi C. Vasopressin V2-receptor blockade with tolvaptan in patients with chronic heart failure: results from a double-blind, randomized trial. Circulation. 2003;107(21):2690-2696.

32. Konstam MA, Gheorghiade M, Burnett JC, Jr., Grinfeld L, Maggioni AP, Swedberg K, Udelson JE, et al. Effects of oral tolvaptan in patients hospitalized for worsening heart failure: the EVEREST Outcome Trial. JAMA. 2007;297(12):1319-1331.

33. Udelson JE, McGrew FA, Flores E, Ibrahim H, Katz S, Koshkarian G, O'Brien T, et al. Multicenter, randomized, double-blind, placebo-controlled study on the effect of oral tolvaptan on left ventricular dilation and function in patients with heart failure and systolic dysfunction. J Am Coll Cardiol. 2007;49(22):2151-2159.

34. Nakada Y, Okayama S, Nakano T, Ueda T, Onoue K, Takeda Y, Kawakami R, et al. Echocardiographic characteristics of patients with acute heart failure requiring tolvaptan: a retrospective study. Cardiovasc Ultrasound. 2015;13:27.

35. Tanaka A, Katsuno T, Ozaki T, Sakata F, Kato N, Suzuki Y, Kosugi T, et al. The efficacy of tolvaptan as a diuretic for chronic kidney disease patients. Acta Cardiol. 2015;70(2):217-223.

36. Shanmugam E, Doss CR, George M, Jena A, Rajaram M, Ramaraj B, Anjaneyan K, et al. Effect of tolvaptan on acute heart failure with hyponatremia - a randomized, double blind, controlled clinical trial. Indian Heart J. 2016;68(Suppl 1):S15-21.

37. Goldsmith SR, Gheorghiade M. Vasopressin antagonism in heart failure. J Am Coll Cardiol. 2005;46(10):17851791.

38. Zeynalov E, Jones SM, Seo JW, Snell LD, Elliott JP. Arginine-Vasopressin Receptor Blocker Conivaptan Reduces Brain Edema and Blood-Brain Barrier Disruption after Experimental Stroke in Mice. PLoS One. 2015;10(8):e0136121.

39. Alskaf E, Tridente A, Al-Mohammad A. Tolvaptan for Heart Failure, Systematic Review and Meta-Analysis of Trials. J Cardiovasc Pharmacol. 2016;68(3):196-203.

40. Yang CJ, Yang J, Fan ZX. Arginine vasopressin antagonist tolvaptan in the treatment of heart failure: a metaanalysis of randomized controlled trials. Int J Clin Exp Med. 2015;8(12):22117-22128.

41. Xiong B, Huang Y, Tan J, Yao Y, Wang C, Qian J, Rong S, et al. The short-term and long-term effects of tolvaptan in patients with heart failure: a meta-analysis of randomized controlled trials. Heart Fail Rev. 2015;20(6):633-642. 